\title{
Heat-regulating polylactic acid/silica aerogel composite fabric: Peparation and characterization
}

\author{
Chin-San $W u^{1 *(\mathbb{D}}$, Dung-Yi $W u^{2}$, Shan-Shue Wang ${ }^{1}$ \\ ${ }^{1}$ Department of Applied Cosmetology, Kao Yuan University, 82101 Kaohsiung County, Taiwan, Republic of China \\ ${ }^{2}$ Department of Materials Science and Engineering, Johns Hopkins University, MD 21218 Baltimore, USA
}

Received 13 June 2021; accepted in revised form 10 August 2021

\begin{abstract}
Heat regulation of the human body through textile fabrics is of great interest to the apparel industry. Herein, blends of environmentally friendly materials, including modified polylactic acid (MPLA) (polylactic acid (PLA) + acrylic acid (AA)-grafted PLA (PLA-g-AA) mixed complex) and silica aerogel (SA) composite, were used to make textiles. The tensile, thermal, heat/cold resistance and surface wettability of the novel composites were characterized. MPLA and SA improved the properties of these composites. The MPLA/SA textiles exhibited more favorable mechanical properties than the PLA/SA textiles; this effect was due to better compatibility between the MPLA and SA. Polylactic acid typically exhibits high hydrophilicity and poor thermal conductivity. Incorporating SA as a filler in the processed yarn significantly enhanced the functional performance of the PLA composite textiles. The addition of SA enhanced hydrophobicity and decreased thermal conductivity, which enabled better temperature regulation. The MPLA/SA textiles displayed superior tensile strength, insulation property, temperature adjustment, water resistance, and washing durability. Moreover, the developed MPLA/SA fabric is suitable for mass production and use in various types of textile goods.
\end{abstract}

Keywords: processing technologies, polylactic acid, silica aerogels, temperature regulation, textile fiber

\section{Introduction}

As global demand for textiles grows, the potential environmental effects resulting from their production, use, and disposal increase accordingly [1-3]. Textile fibers are primarily made from petrochemical materials, such as polyethylene terephthalate (PET) [4], nylon [5], and polypropylene [6]. Unused textile fibers are typically incinerated, which contributes to environmental pollution [7, 8]. Environmental considerations are of increasing importance, and the development of environmentally friendly materials guarantees sustainable growth of the textile industry. Extensive research regarding biodegradable fibers, commonly polylactic acid (PLA)-based, has been conducted during the past decade [9-10].

PLA fiber can be synthesized from renewable resources. Its heat of combustion is only one-third of the corresponding heat needed for PET. PLA fiber is readily decomposed into $\mathrm{CO}_{2}$ and water during composting; it is environmentally friendly $[11,12]$. The fiber has excellent performance features, including higher hydrophilicity than PET, low density, good tensile properties, and biodegradability [13-15]. It is used for clothing and nonwoven fabrics. For example, Feng et al. [16] prepared a composite fiber yarn from polyhydroxyalkanoates (PHAs) and PLA, which are biodegradable plastics. The yarn had good air permeability, water vapor permeability, and crease restorability. Baghaei and Skrifvars [17] blended PLA with hemp to form a complex yarn that was made into a nonwoven fabric. The impact resistance, flexural strength, and tensile strength of the nonwoven fabric were significantly enhanced. However, a PLA fiber-based textile is not commercially viable due to

\footnotetext{
${ }^{*}$ Corresponding author, e-mail: t50008@cc.kyu.edu.tw (C) BME-PT
} 
its poor hydrolysis resistance and heat retention, which lead to poor durability. Reinforcement with silica aerogel (SA) helps to solve this issue; the composite textile has enhanced water resistance, mechanical properties, and heat retention.

SA has excellent hydrophobicity and thermal insulating properties. It is prepared by a sol-gel method and processed through various supercritical or drying methods to form a nanoparticle assembly with an internal $\mathrm{SiO}_{2}$ crosslinked structure. The enhanced properties of SA make it highly suitable as a textile fiber material [18-21]. Islam et al. [22] prepared and characterized a composite fabric prepared from a high polymer and aerogel. Retention of air within the fabric fibers enhanced the thermal resistance.

Kiekens et al. [23] noted that multifunctional textiles are becoming increasingly important. Demand for functional textiles with heat/cold resistance, water repellency, and good mechanical properties, which are derived from biobased materials, is rapidly growing. Functional textile fabrics that regulate energy flow between the human body and the environment to promote human health and comfort are of great interest to the clothing industry [24]. Temperature regulation of the cold/heat energy between the human body and the environment is usually achieved by coating temperature-regulating materials on the fabric surface $[25,26]$. However, such coating material is readily removed during washing and thus loses its regulatory function. To address this shortcoming, nanoporous ceramic materials are directly incorporated into biobased polyester polymers, which are drawn into yarns and then woven into textile fabrics. Washing does not remove the ceramic coating material, so the temperature-regulating function is retained. Hence, a composite material composed of organic matter and a ceramic material made into yarn is of great interest. Herein, we prepared a functional textile fiber material by combining SA with biobased PLA substrate. The composite was spun into fibers that were formed into the fabric using a plain-weave technique. Pretreatment of the aerogel and PLA enhanced the cohesion of the composite. First, a nanoscale SA powder was prepared via wet lapping. Modified PLA (MPLA), prepared by treating PLA with acrylic acid (AA), served as a compatibilizer. The MPLA and aerogel powder were blended; a filter screen installed in the thermal processing equipment head removed impurities and enhanced aerogel dispersion. The finished yarn and fabric were formed

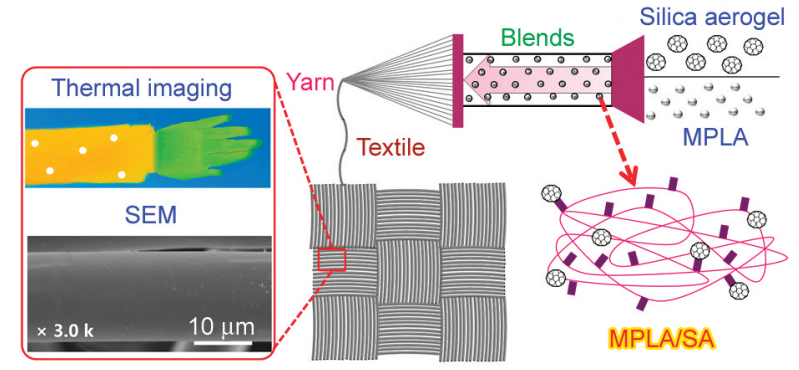

Figure 1. Fabrication of MPLA/SA yarn and textile from modified polylactic acid (MPLA) and silica aerogel (SA).

through a spinning process. The structure, mechanical strength, water resistance, heat/cold resistance, and thermal properties of various MPLA/SA composites were characterized. Thermally regulating fiber composites have recently been reported [27, 28]. Here, we successfully fabricated fabric textiles containing modified polylactic acid (MPLA) and SA that provided passive thermal regulation. To summarizing, a new functional regulating composite yarn was designed and woven into a fabric displaying excellent washing resistance and temperature regulation (Figure 1).

\section{Experimental}

\subsection{Materials}

Polylactide (PLA) composed of 95\% L-lactide (Purapol L130; density $=1.24 \mathrm{~g} / \mathrm{cm}^{3}$ ) and $5 \%$ meso-lactide (Purapol D070; density $=1.24 \mathrm{~g} / \mathrm{cm}^{3}$ ) were supplied by Corbion Purac (Amsterdam, The Netherlands). SAs (trimethylsilated content $>98 \%$, density $=0.04-0.1 \mathrm{~g} / \mathrm{cm}^{3}$, specific surface areas $=850$ and $1050 \mathrm{~m}^{2} / \mathrm{g}$, porosity $>93 \%$, and thermal conductivity $=0.031 \mathrm{~W} \cdot \mathrm{m}^{-1} \cdot \mathrm{K}^{-1}$ was supplied by JIOS Aerogel Pro. Co. (Gyeonggi-do, Korea). AA, dicumyl peroxide, and ethanol were obtained from Aldrich Chemical Co. (Milwaukee, WI, USA). The grafting of AA to PLA was done using a similar method to that used in our previous research; the grafting percentage was $5.96 \mathrm{wt} \%$ [29].

\subsection{Fabrication of MPLA/SA textiles}

SA powder $(50-200 \mu \mathrm{m})$ was soaked in ethanol $(1: 25, w / w)$, mixed thoroughly, and ground in a water mill $(1.5 \mathrm{HP}, 60 \mathrm{~Hz})$ at $3600 \mathrm{rpm}$ for $12 \mathrm{~h}$. The fraction consisting of particles smaller than $20-80 \mathrm{~nm}$ was dried at $80^{\circ} \mathrm{C}$ for 2 days.

SA was oven-dried at $110^{\circ} \mathrm{C}$ for 1 day before composite fabrication. The weight ratios of SA to PLA or MPLA were 0.3/99.7, 0.6/99.4, 0.9/99.1, and 1.2/98.8. 


\section{TIITाITाIITाT PLA}

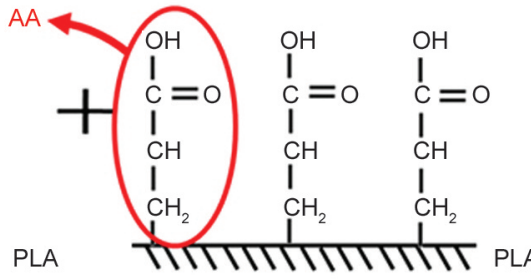

PLA-g-AA

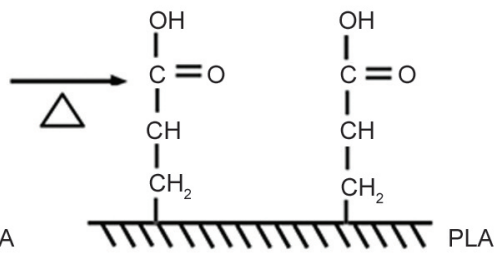

MPLA
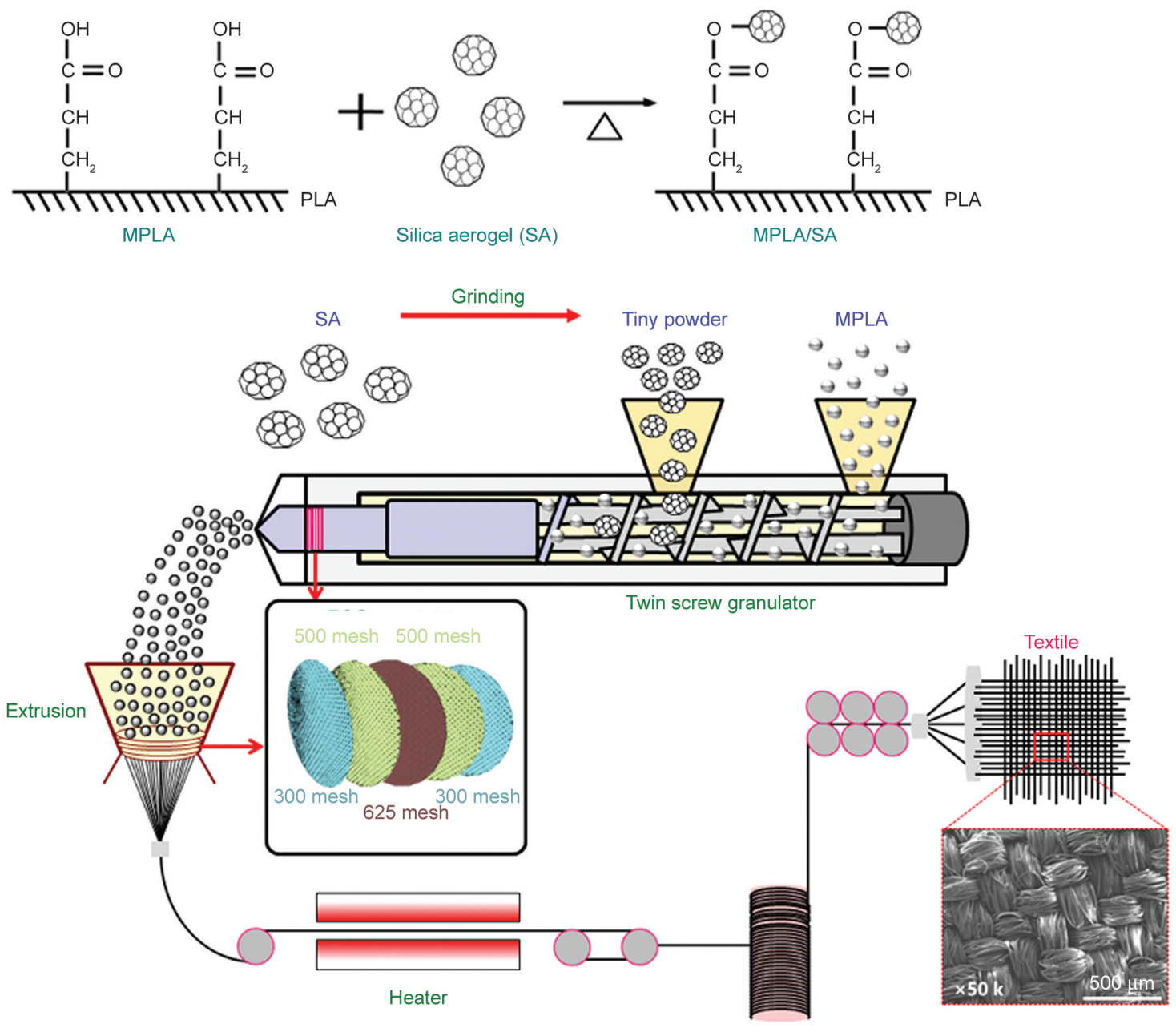

c)

Yarn

Figure 2. Schematic diagram showing the fabrication of MPLA/SA composites containing modified polylactic acid (MPLA) and silica aerogel (SA). (a, b) Chemical reaction. (c) Processing of mixed MPLA/SA melts into yarns, and drawing and false-twisting of the yarns into MPLA/SA textiles.

The composites were made in an extruder with a corotating screw (PSM 50A; Polyalloy Inc., Taoyan, Taiwan). The composites were then blended at 180 $200^{\circ} \mathrm{C}$ for $2 \mathrm{~min}$ at $200 \mathrm{rpm}$. Various filter screens were used to enhance the dispersion of SA in PLA or MPLA and for casting parts. Figure 2a, $2 b$ illustrates the fabrication process, and Table 1 details the composition of each prepared specimen.

The fabricated MPLA/SA particles were dried at $50{ }^{\circ} \mathrm{C}$ for $18 \mathrm{~h}$. The particles were extruded under conditions of 1.8 bar and $180-240^{\circ} \mathrm{C}$ to produce a series of yarns. A line heater operating at $80^{\circ} \mathrm{C}$ and
$4000 \mathrm{~m} / \mathrm{min}$ was used to pull the yarns into fibers having a mean length of $38 \mathrm{~mm}$ and fineness of $40 \pm 3 \%$. Textiles of each MPLA/SA composition were prepared by false twisting (36 \pm 1 ) with tatting (3.6)) (Figure 2c).

\subsection{Characterization}

PLA, modified PLA, and their composites were examined by Fourier transform-infrared (FT-IR) spectroscopy and X-ray diffraction (XRD) [30]. Tensile testing of the fabricated 50D/36f filament yarn and textile composites was conducted using a universal 
Table 1. Formulation of PLA/SA and MPLA/SA composites.

\begin{tabular}{|c|c|c|c|}
\hline \multirow[b]{2}{*}{ Sample code } & \multicolumn{3}{|c|}{ Component } \\
\hline & $\begin{array}{c}\text { PLA } \\
\text { [wt\%] }\end{array}$ & $\begin{array}{c}\text { PLA-g-AA } \\
\text { [phr] }\end{array}$ & SA \\
\hline PLA & 100.0 & - & - \\
\hline PLA/SA 0.3 wt $\%$ & 99.7 & - & 0.3 \\
\hline PLA/SA 0.6 wt $\%$ & 99.4 & - & 0.6 \\
\hline PLA/SA 0.9 wt $\%$ & 99.1 & - & 0.9 \\
\hline PLA/SA $1.2 \mathrm{wt} \%$ & 98.8 & - & 1.2 \\
\hline MPLA & 100.0 & 10.0 & - \\
\hline MPLA/SA $0.3 \mathrm{wt} \%$ & 99.7 & 10.0 & 0.3 \\
\hline MPLA/SA $0.6 \mathrm{wt} \%$ & 99.4 & 10.0 & 0.6 \\
\hline MPLA/SA $0.9 \mathrm{wt} \%$ & 99.1 & 10.0 & 0.9 \\
\hline MPLA/SA $1.2 \mathrm{wt}^{\circ} \%$ & 98.8 & 10.0 & 1.2 \\
\hline
\end{tabular}

PLA: polylactide; MPLA: modified PLA; SA: silica aerogel.

testing machine (model HT-9102; Hung Ta Instrument Co., Ltd., Taichung, Taiwan) operating with a $10 \mathrm{~mm} / \mathrm{min}$ crosshead speed and $10 \mathrm{~mm}$ gauge length.

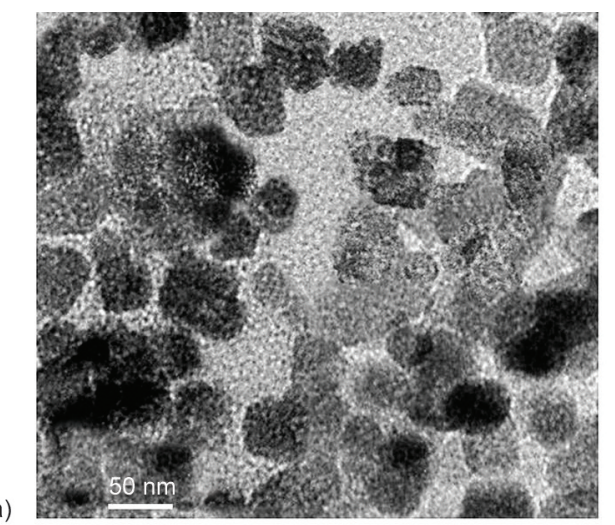

The fibers were conditioned at $25 \pm 1{ }^{\circ} \mathrm{C}(60 \pm 2 \%$ relative humidity) for $>1$ day, and testing was then performed. Laundering durability was evaluated using a standard method similar to that reported in [31]. Briefly, a specimen was immersed in a tank containing 10 steel balls and $300 \mathrm{ml}$ of soap solution at $45^{\circ} \mathrm{C}$ for 1 day. Then, the specimen was washed using a six-cycle program.

The SA particle size distribution was determined using a particle size instrument [32]. The SA samples were dispersed in water under ultrasonic agitation for $30 \mathrm{~min}$. The SA was also examined by transmission electron microscopy [30]. The micrographs in Figure 3a show the SA morphology and Figure 3b presents the particle size distribution. Particle sizes ranged from 20 to $80 \mathrm{~nm}$. The yarn surface was measured by scanning electron microscopy (SEM) [31]. Compared with the PLA/SA and MPLA/SA fibers,

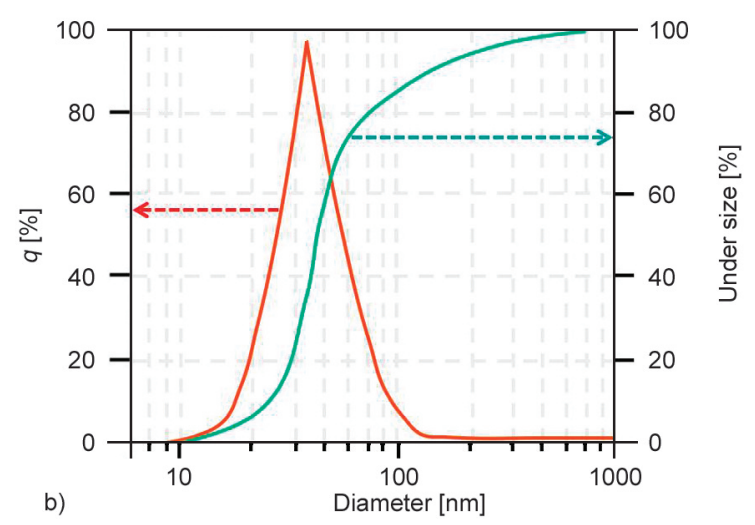

Figure 3. (a) Transmission electron micrographs and (b) particle size distributions of SA.

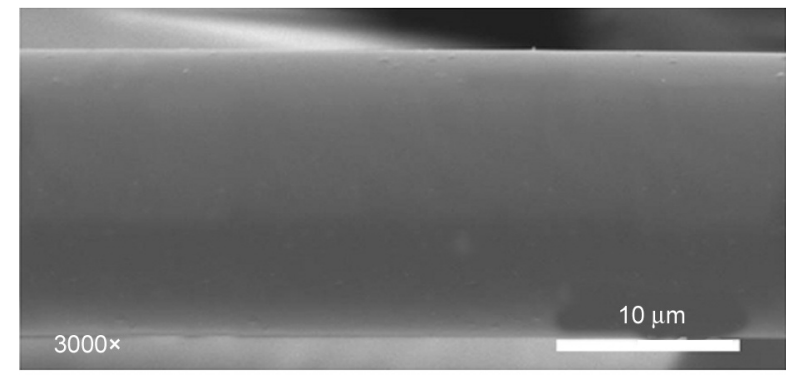

a)

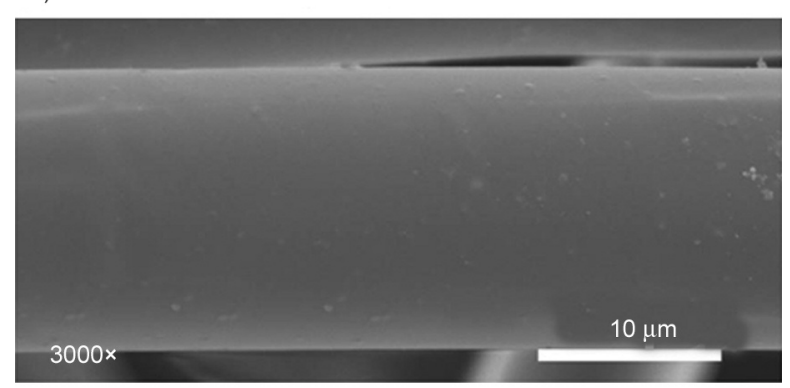

c)

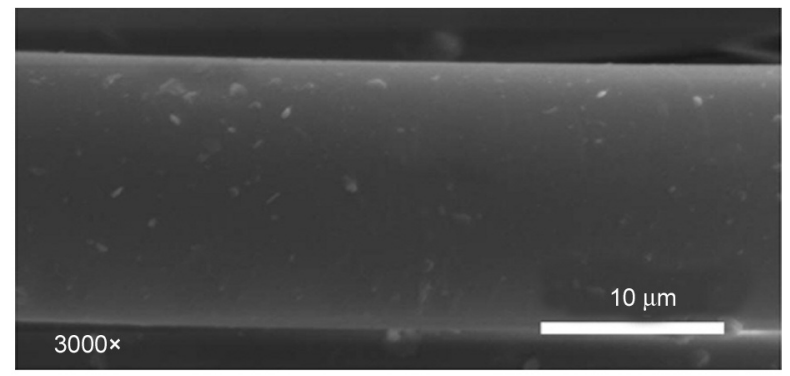

b)

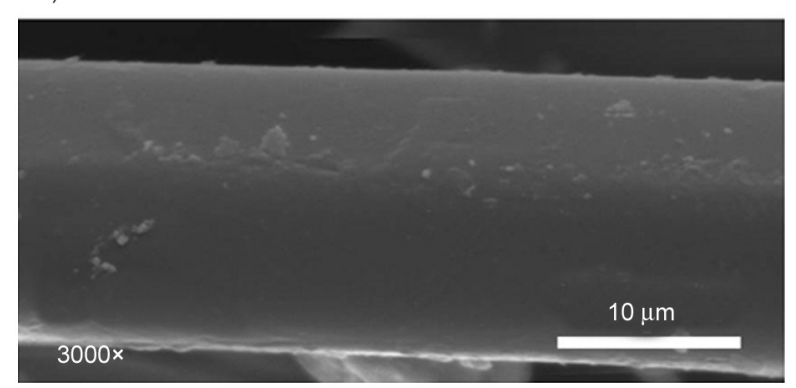

d)
MPLA/SA 1.2 wt\%

Figure 4. Scanning electron microscopy images showing the distribution of SA powder in the PLA or MPLA fabric samples. a) PLA, b) PLA/SA $0.6 \mathrm{wt} \%$, c) MPLA/SA $0.6 \mathrm{wt} \%$, d) MPLA/SA $1.2 \mathrm{wt} \%$. 
the surface of the pure PLA fiber was smoother and free of spots (Figure 4). The rough surface and spots scattered across the PLA/SA composite yarn surface were particularly notable. The surface of the MPLA/ SA composite yarn was smoother, had fewer spots, and demonstrated a more uniform texture compared with the PLA/SA composite yarn. Mottle and irregular area increased with increasing SA content, and the yarn breakage rate was high when the SA content exceeded $1.2 \%$ by weight. Poor dispersion and agglomeration occurred when the SA content exceeded this level, which led to yarn breakage.

\subsection{Thermal property measurements}

The thermal properties of PLA, modified PLA, and their composites were examined by differential scanning calorimetry (DSC) and thermogravimetric analysis (TGA) [31]. The thermal conductivity and thermal diffusivity of the PLA/SA and MPLA/SA fabrics were measured using a thermal constants analyzer (Hot Disk 2500; Hot Disk AB, Göteborg, Sweden) at $25^{\circ} \mathrm{C}$. The textile fabric was made for evaluation by people. The fabric cloth was tied to the right arm, and the subject remained at a $45 \%$ relative humidity and 20 or $40^{\circ} \mathrm{C}$ for $0.5 \mathrm{~h}$. A FLIR ONE PRO (FLIR Systems Inc., Wilsonville, OR, USA) thermal imaging system was used to obtain infrared images of the textile samples. All acquired photographs and data were archived and recorded on a computer. Each test was conducted five times with an interval of at least $3 \mathrm{~h}$ between each test. Data are shown as the mean of six replicates.

\section{Results and discussion}

\subsection{Structural analyses of PLA and its composites}

The FT-IR spectra of PLA, MPLA, SA, PLA/SA, and MPLA/SA are presented in Figure 5. Absorption bands for PLA appeared in the ranges of 3300-3700, 1700-1760, and 500-1500 $\mathrm{cm}^{-1}$ (Figure 5 curve a); MPLA displayed an additional shoulder at $1710 \mathrm{~cm}^{-1}$ (Figure 5 curve b). These findings agree with previously reported data [33]. The carboxyl groups in the modified polymer (AA grafted onto PLA) resulted in an additional shoulder.

The intensity of the peak at $3200-3600 \mathrm{~cm}^{-1}(-\mathrm{OH}$ stretching vibration) was higher in the $0.6 \mathrm{wt} \% \mathrm{PLA} /$ SA and $0.6 \mathrm{wt} \% \mathrm{MPLA} / \mathrm{SA}$ composites (Figure 5 curve $\mathrm{c}$, and curve d) due to the participation of SA $-\mathrm{OH}$ groups. The SA spectrum (Figure 5 curve e) showed typical absorption peaks at $3200-3600 \mathrm{~cm}^{-1}$

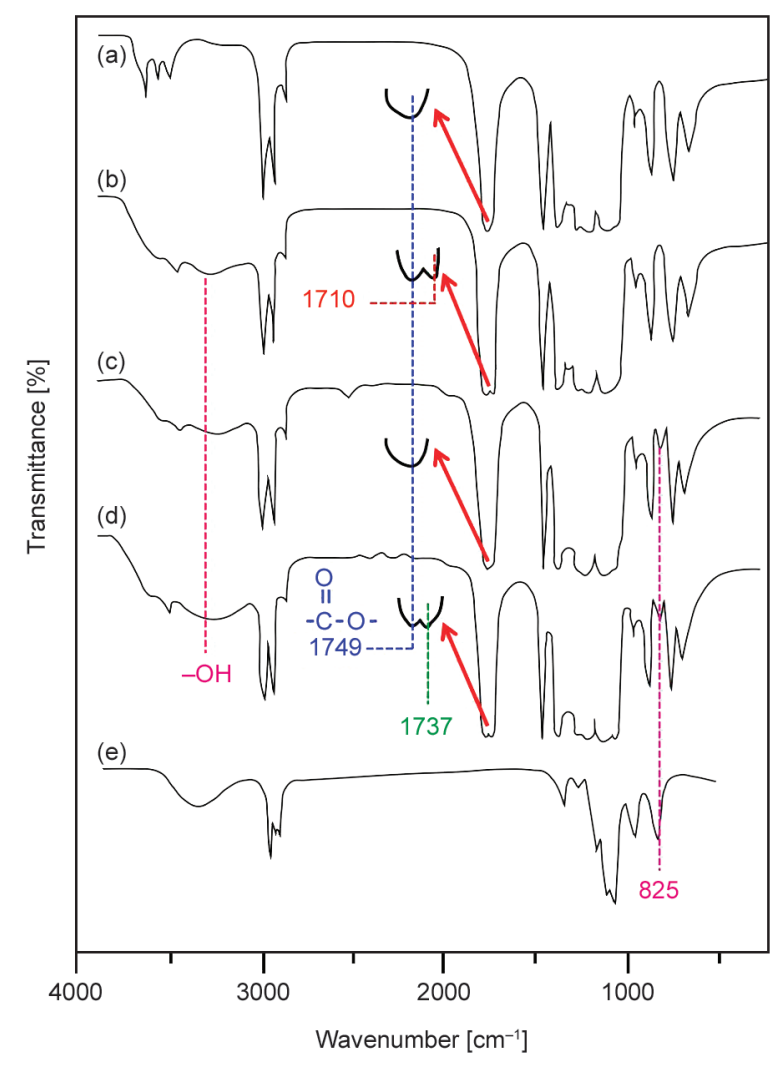

Figure 5. Fourier transform-infrared spectra of (a) PLA, (b) MPLA, (c) $0.6 \mathrm{wt} \%$ PLA/SA, (d) $0.6 \mathrm{wt} \%$ MPLA/SA composites and (e) SA.

(hydroxyl groups), 2850-2950 $\mathrm{cm}^{-1}$ (C-H stretching), $1050-1200 \mathrm{~cm}^{-1}$ (Si-O-Si asymmetric bending), and $800-850 \mathrm{~cm}^{-1}$ ( $\mathrm{Si}-\mathrm{O}-\mathrm{Si}$ symmetric stretching) [34]. Silica is the main inorganic component of SA. A peak that appeared at $1,737 \mathrm{~cm}^{-1}$ in the MPLA/SA $(0.6 \mathrm{wt} \%)$ composite spectrum was attributed to the $-\mathrm{C}=\mathrm{O}$ stretching vibration of the $-\mathrm{OCOR}$ group; this peak was not present in the PLA/SA $(0.6 \mathrm{wt} \%)$ spectrum [35]. These ester groups resulted from the reaction of AA groups of MPLA with HO-Si groups of SA.

XRD analysis revealed the crystalline structure of PLA, 0.6 wt\% PLA/SA, $0.6 \mathrm{wt} \%$ MPLA/SA, and SA (Figure 6). Two peaks at approximately $16.9^{\circ}$ (1) and $19.7^{\circ}(2)$ appeared in the PLA diffractogram (Figure 6 curve a), in agreement with a previous report [36]. An additional peak at approximately $23.3^{\circ}$ (3) in the X-ray diffraction spectra of the PLA/ SA composites (Figure 6 curve b) was attributed to SA (Figure 6 curve d) [37] after comparison with the pristine PLA diffractogram (Figure 6 curve a); these results indicated good dispersion of SA in the PLA matrix. A new peak present at $2 \theta=18.1^{\circ}(4)$ in the MPLA/SA composites diffractograms (Figure 6 


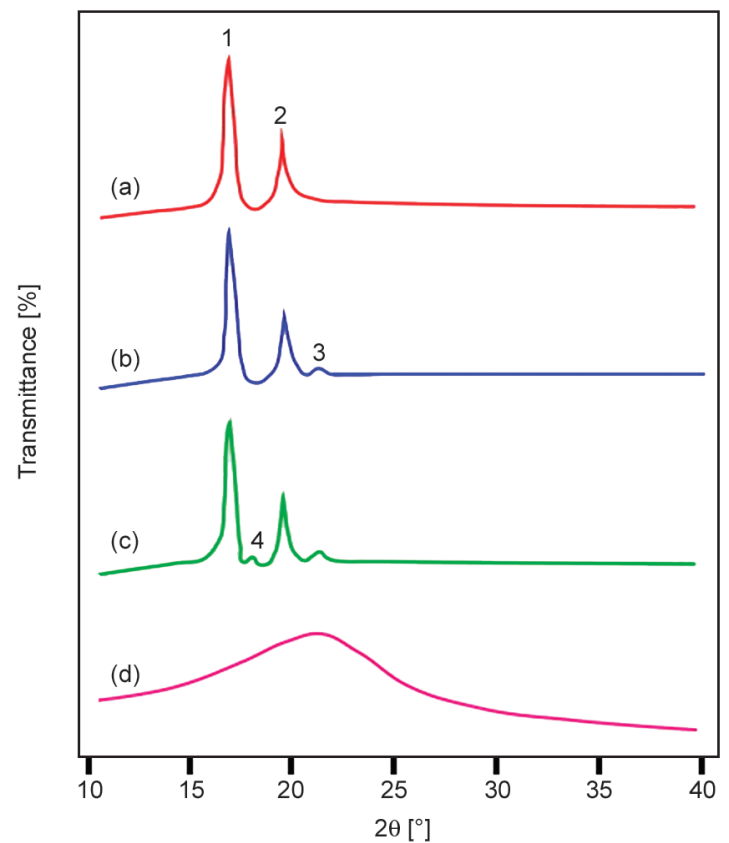

Figure 6. X-ray diffractograms of (a) PLA, (b) $0.6 \mathrm{wt} \%$ PLA/SA, (c) $0.6 \mathrm{wt} \%$ MPLA/SA composites, and (d) SA.

curve c) was not present in the PLA/SA composites diffractograms (Figure 6 curve b). A new ester bond formed between the AA of MPLA and HO of SA in the MPLA/SA composite, in agreement with a previous report [38]. This also provides molecular evidence that PLA/SA and MPLA/SA have different crystalline structures.

\subsection{Tensile properties and surface wettability of PLA and its composites}

Figure 7 and Table 2 show the tenacity and elongation at break of the PLA/SA and MPLA/SA composite filaments. The PLA/SA and MPLA/SA yarns displayed characteristic behavior in their tenacity at break, which increased with increasing SA content up to $0.6 \mathrm{wt} \%$ and then slightly decreased. In addition, the tenacity at break of MPLA/SA was approximately $0.26-0.81 \mathrm{cN} /$ dtex higher, respectively, than the tenacity at break of PLA/SA. This

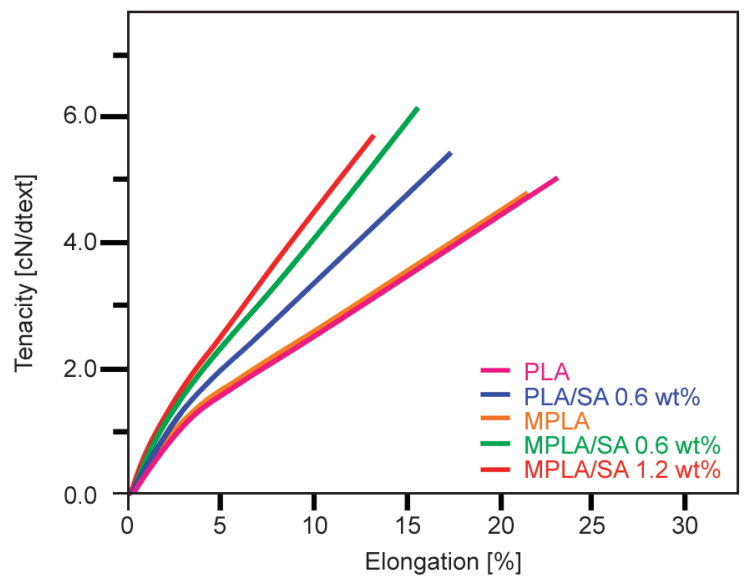

Figure 7. Tensile behavior. Stress-strain curves of PLA, MPLA, PLA/SA, and MPLA/SA yarns.

phenomenon was due to enhanced SA adhesion to MPLA.

For the PLA/SA and MPLA/SA yarns, the elongation at break also decreased with increasing SA content, while the pristine PLA yarn displayed higher values. Compared with the PLA yarn, the increase of tenacity and decrease of elongation at break of the PLA/SA and MPLA/SA yarns was attributed to the rigidity of the SA material.

The surface polarities of PLA, PLA/SA, and MPLA/ SA composites were examined by water contact angle analysis (Figure 8). The contact angle on pure PLA was $92.31 \pm 3.05^{\circ}$ and water was absorbed (Figure $8 \mathrm{a}$ ). The PLA/SA (0.6 wt\%) and PLA/SA (1.2 wt\%) composites had contact angles of $111.92 \pm 3.96$ and $121.35 \pm 4.12^{\circ}$, respectively, which was attributed to the hydrophobicity of SA. This behavior was also noticed with the MPLA/SA composites and increased with increasing SA concentration. Thus, water resistance can be increased by adding SA to PLA or MPLA-based composites [39, 40]. Moreover, at the same SA loading, composites containing PLA/SA had contact angles that were about $4.0-5.5^{\circ}$ $(0.6 \mathrm{wt} \%)$ or $7.0-8.0^{\circ}(1.2 \mathrm{wt} \%)$ lower than the contact angles of composites containing MPLA/SA.

Table 2. Tensile properties of PLA/SA and MPLA/SA filaments.

\begin{tabular}{|c|c|c|c|c|}
\hline \multirow{2}{*}{$\begin{array}{c}\text { SA } \\
{[\mathbf{w t} \%]}\end{array}$} & \multicolumn{2}{|c|}{ PLA/SA } & \multicolumn{2}{c|}{ MPLA/SA } \\
\cline { 2 - 5 } & $\begin{array}{c}\text { Tenacity } \\
{[\mathbf{c N} / \mathbf{d t e x}]}\end{array}$ & $\begin{array}{c}\text { Elongation } \\
{[\%]}\end{array}$ & $\begin{array}{c}\text { Tenacity } \\
{[\mathbf{c N} / \mathbf{d t e x}]}\end{array}$ & $\begin{array}{c}\text { Elongation } \\
{[\%]}\end{array}$ \\
\hline 0.0 & $5.21 \pm 0.28$ & $24.31 \pm 0.48$ & $5.19 \pm 0.29$ & $22.35 \pm 0.48$ \\
\hline 0.3 & $5.46 \pm 0.29$ & $21.02 \pm 0.52$ & $5.72 \pm 0.35$ & $19.03 \pm 0.50$ \\
\hline 0.6 & $5.65 \pm 0.32$ & $17.79 \pm 0.55$ & $6.46 \pm 0.36$ & $15.96 \pm 0.52$ \\
\hline 0.9 & $5.50 \pm 0.35$ & $15.25 \pm 0.56$ & $6.20 \pm 0.38$ & $14.78 \pm 0.53$ \\
\hline 1.2 & $5.38 \pm 0.38$ & $13.96 \pm 0.58$ & $5.98 . \pm 0.39$ & $13.86 \pm 0.55$ \\
\hline
\end{tabular}




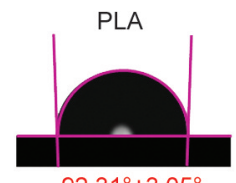

$92.31^{\circ} \pm 3.05^{\circ}$

PLA/SA 0.6 wt $\%$

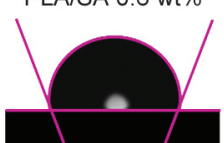

$111.92^{\circ} \pm 4.2^{\circ}$

PLA/SA $1.2 w t \%$

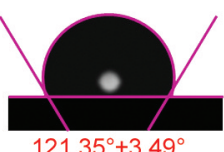

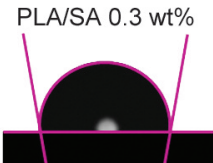

$100.91^{\circ} \pm 3.96^{\circ}$ MPLA/SA $0.6 w t \%$

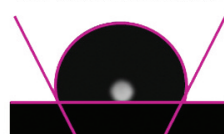

$117.21^{\circ} \pm 4.10^{\circ}$ MPLA/SA $1.2 \mathrm{wt} \%$

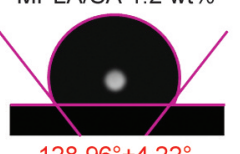

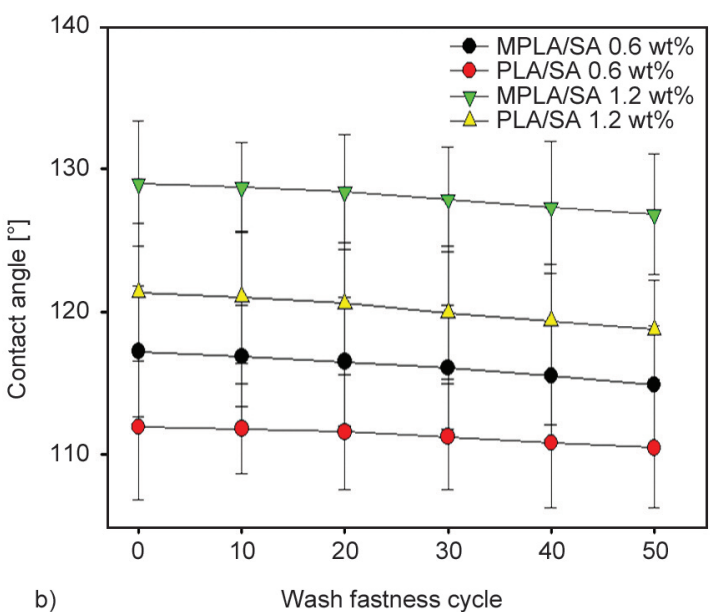

Figure 8. (a) Contact angles of PLA, and PLA/SA and MPLA/SA composites. (b) Contact angle changes of PLA, and PLA/SA and MPLA/SA composites as a function of washing cycle.

The washing resistance of the composite textiles was demonstrated by their water contact angles (Figure 8b). As the number of washing cycles increased to 50 , only a slight decrease in the water contact angles of PLA/SA (0.6 and $1.2 \mathrm{wt} \%)$ and MPLA/SA (0.6 and $1.2 \mathrm{wt} \%$ ) composite textiles were observed. This indicated that the PLA/SA $(0.6$ and $1.2 \mathrm{wt} \%$ ) and MPLA/SA (0.6 and $1.2 \mathrm{wt} \%)$ composite textiles were still highly hydrophobic. The PLA/SA (0.6 and $1.2 \mathrm{wt} \%)$ and MPLA/SA (0.6 and $1.2 \mathrm{wt} \%)$ composite textiles displayed superior laundering durability.

\subsection{Thermal properties of PLA and its composites}

Figure 9 presents DSC heating thermograms and Table 3 summarizes the melting enthalpy $\left(\Delta H_{\mathrm{m}}\right)$, glass transition temperature $\left(T_{\mathrm{g}}\right)$, and melting temperature $\left(T_{\mathrm{m}}\right)$ of the PLA/SA and MPLA/SA composites comprising various quantities of SA. The presence of SA did not dramatically affect the $T_{\mathrm{m}}$. A loose polymeric structure in the PLA/SA and MPLA/ SA composites was induced by SA addition. The MPLA/SA composites had lower $T_{\mathrm{m}}$, compared with the PLA/SA composites, at a specific SA content;

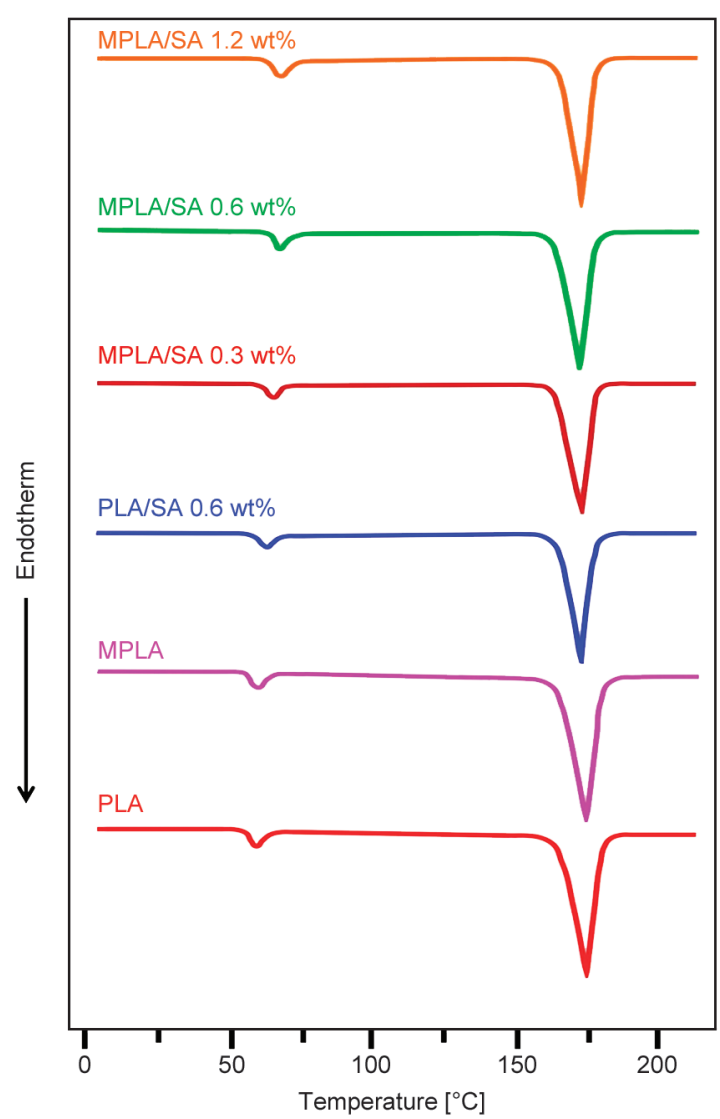

Figure 9. Differential scanning calorimetry scans of PLA, MPLA, and PLA/SA and PLA/SA composites.

Table 3. Differential scanning calorimetry data for PLA/SA and MPLA/SA composites.

\begin{tabular}{|c|c|c|c|c|c|c|}
\hline \multirow{2}{*}{$\begin{array}{c}\text { SA } \\
{[\mathbf{w t} \%]}\end{array}$} & \multicolumn{3}{|c|}{ PLA/SA } & \multicolumn{3}{c|}{ MPLA/SA } \\
\cline { 2 - 7 } & $\begin{array}{c}\boldsymbol{T}_{\mathbf{g}} \\
{\left[{ }^{\circ} \mathbf{C}\right]}\end{array}$ & $\begin{array}{c}\boldsymbol{T}_{\mathbf{m}} \\
{\left[{ }^{\circ} \mathbf{C}\right]}\end{array}$ & $\begin{array}{c}\Delta \boldsymbol{H}_{\mathbf{m}} \\
{[\mathbf{J} / \mathbf{g}]}\end{array}$ & $\begin{array}{c}\boldsymbol{T}_{\mathbf{g}} \\
{\left[{ }^{\circ} \mathbf{C}\right]}\end{array}$ & $\begin{array}{c}\boldsymbol{T}_{\mathbf{m}} \\
{\left[{ }^{\circ} \mathbf{C}\right]}\end{array}$ & $\begin{array}{c}\Delta \boldsymbol{H}_{\mathbf{m}} \\
{[\mathbf{J} / \mathbf{g}]}\end{array}$ \\
\hline 0.0 & 55.7 & 174.3 & 38.1 & 55.2 & 174.1 & 37.9 \\
\hline 0.3 & 57.0 & 173.2 & 34.1 & 61.4 & 172.3 & 36.6 \\
\hline 0.6 & 59.1 & 172.5 & 31.1 & 64.3 & 171.8 & 35.5 \\
\hline 0.9 & 58.9 & 172.8 & 28.8 & 63.7 & 172.0 & 34.2 \\
\hline 1.2 & 58.4 & 173.3 & 26.6 & 62.6 & 172.3 & 33.1 \\
\hline
\end{tabular}


moreover, SA enhanced the $T_{\mathrm{g}}$ of both types of composites, which is consistent with the greater molecular motion restriction in the presence of SA [41]. Greater $T_{\mathrm{g}}$ (by $3.5-5.0^{\circ} \mathrm{C}$ ) of the MPLA composites was attributed to bridge formation between SA and MPLA, which restricted molecular movement.

The $\Delta H_{\mathrm{m}}$ of PLA $\left(38.1 \mathrm{~J} \cdot \mathrm{g}^{-1}\right)$ was slightly higher than the $\Delta H_{\mathrm{m}}$ of MPLA $\left(37.9 \mathrm{~J} \cdot \mathrm{g}^{-1}\right)$. The lower $\Delta H_{\mathrm{m}}$ of MPLA is due to grafted branches that disrupted the regularity of the chain structures in PLA and increased the spacing between polymer chains. The difference in $\Delta H_{\mathrm{m}}$ of $2.5-6.5 \mathrm{~J} \cdot \mathrm{g}^{-1}$ between the MPLA/SA composites and PLA/SA analogs was related to the condensation reaction. For both PLA/SA and MPLA/SA composites, increasing SA content resulted in decreasing $\Delta H_{\mathrm{m}}$ (Table 3) [42]. However, the PLA/SA cases displayed a larger $\Delta H_{\mathrm{m}}$ decrement, which indicated lower crystallinity.

Figure 10 presents TGA thermograms and Table 4 summarizes the residual yields and initial decomposition temperatures at $5 \%$ weight loss $\left(T_{5 \%}\right)$ of the PLA/SA and MPLA/SA composites as a function of SA content. There was no decomposition up to $250^{\circ} \mathrm{C}$, and only minor decomposition from 250 to $350^{\circ} \mathrm{C}$ for SA, PLA, and PLA/SA and MPLA/SA

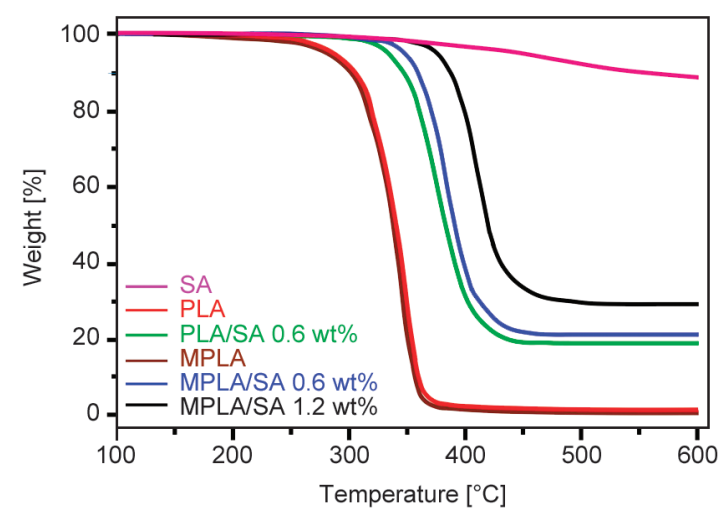

Figure 10. Thermogravimetric analysis curves of SA, PLA, MPLA, and $0.6 \mathrm{wt} \%$ PLA/SA and $0.6 \mathrm{wt} \%$ MPLA/SA composites. composites (Figure 10). Above $350^{\circ} \mathrm{C}$, decomposition rapidly increased for PLA, MPLA, PLA/SA $0.6 \mathrm{wt} \%$, and MPLA/SA $0.6 \mathrm{wt} \%$, with $0.5,0.4$, 19.6 , and $20.5 \%$ residual yields at $500^{\circ} \mathrm{C}$, respectively (Table 4 and Figure 10). The $T_{5 \%}$ increased with increasing SA content (Table 4) due to the inhibition of PLA or MPLA chain mobility. SA is a framework structure of heat-resistant material [43]. As SA was heated over $600^{\circ} \mathrm{C}$, its weight loss remained within $15 \%$ (Figure 10). Hence, the addition of SA to PLA or MPLA enhanced the rigidity of the PLA/SA and MPLA/SA composites due to SA inhibiting the mobility of the PLA or MPLA chains. Reduced thermal degradation of the composites was indicated by the higher IDTs. For the same SA amount, the PLA/SA composites had lower $T_{5 \%}$, compared with the MPLA/ SA composites, because the bonding between MPLA and SA increased the thermal resistance of the composites. The $T_{5 \%}$ of the PLA/SA composites were about $6-20^{\circ} \mathrm{C}$ lower than those of the MPLA/SA composites. Comparison of the PLA and MPLA/SA composites revealed $T_{5 \%}$ increases of about $58^{\circ} \mathrm{C}$ with $0.6 \mathrm{wt} \%$ and $82^{\circ} \mathrm{C}$ with $1.2 \mathrm{wt} \% \mathrm{SA}$, thus comprising a $24^{\circ} \mathrm{C}$ improvement from 0.6 to $1.2 \mathrm{wt} \%$ SA. This again shows that $0.6 \mathrm{wt} \% \mathrm{SA}$ is the optimal loading. When the SA loading exceeded $0.6 \mathrm{wt} \%$, the particle dispersion was negatively affected. Residual yields also improved with increasing SA content (Table 4). This indicated that a more thermally stable polymer matrix was formed in the PLA/SA or MPLA/ SA composites. The release of decomposition products from the polymer matrix was hindered by SA. Char layer formation increased due to thermal stability and an SA network formed in the polymer/SA composites. Diffusion of volatile fragments during polymer degradation accordingly decreased [44]. The TGA data also indicate that the thermal stability of the PLA/SA or MPLA/SA composites was greatly enhanced by adding small quantities of SA.

Table 4. Effect of SA content on the decomposition temperature and char residue of PLA/SA and MPLA/SA composites.

\begin{tabular}{|c|c|c|c|c|}
\hline \multirow{2}{*}{$\begin{array}{c}\text { SA } \\
{[\mathbf{w t} \%]}\end{array}$} & $\begin{array}{c}|c| \\
\text { IDTs, 5\% } \\
{\left[{ }^{\circ} \mathbf{C}\right]}\end{array}$ & $\begin{array}{c}\text { Phar residue } \\
{[\%]}\end{array}$ & $\begin{array}{c}\text { MDTs, 5\% } \\
{\left[{ }^{\mathbf{C}} \mathbf{C}\right]}\end{array}$ & $\begin{array}{c}\text { MPLar residue } \\
{[\%]}\end{array}$ \\
\hline 0.0 & 296 & 0.5 & 293 & 0.4 \\
\hline 0.3 & 320 & 10.2 & 326 & 10.8 \\
\hline 0.6 & 342 & 19.6 & 354 & 20.5 \\
\hline 0.9 & 359 & 24.8 & 370 & 25.9 \\
\hline 1.2 & 369 & 28.6 & 378 & 29.5 \\
\hline
\end{tabular}

IDTs: initial decomposition temperature at $5 \mathrm{wt} \%$ loss. 

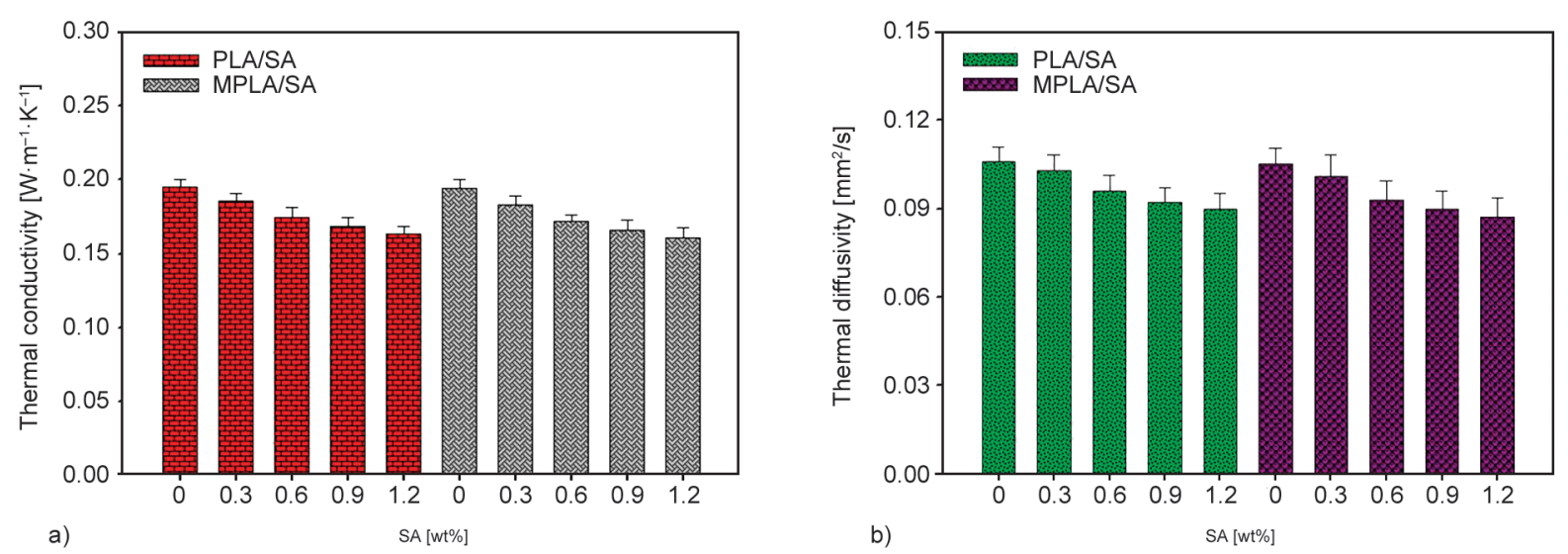

Figure 11. (a) Thermal conductivity and (b) thermal diffusivity of PLA/SA and MPLA/SA fibers.

The insulating properties of textile products are mainly determined by their thermal conductivity and thermal diffusivity $[31,45,46]$. Figure 11 shows that the thermal conductivity and thermal diffusivity of the PLA/SA and MPLA/SA fabrics were lower than those of the PLA fabric. These two factors clearly decreased with increasing SA content, and ranged from $0.195 \mathrm{~W} \cdot \mathrm{m}^{-1} \cdot \mathrm{K}^{-1} / 0.106 \mathrm{~mm}^{2} \cdot \mathrm{s}^{-1}$ to

$0.163 \mathrm{~W} \cdot \mathrm{m}^{-1} \cdot \mathrm{K}^{-1} / 0.090 \mathrm{~mm}^{2} \cdot \mathrm{s}^{-1}$ and $0.161 \mathrm{~W} \cdot \mathrm{m}^{-1} \cdot \mathrm{K}^{-1} / 0.087 \mathrm{~mm}^{2} \cdot \mathrm{s}^{-1}$ for the PLA/SA and MPLA/SA textiles, respectively (Figure 11). These changes became less pronounced when the SA concentration exceeded $0.6 \mathrm{wt} \%$; this was attributed to SA aggregation. Moreover, the thermal conductivity and thermal diffusivity of the MPLA/SA textile were $0.002-0.003 \mathrm{~W} \cdot \mathrm{m}^{-1} \cdot \mathrm{K}^{-1}$ and $0.002-$ $0.003 \mathrm{~mm}^{2} \cdot \mathrm{s}^{-1}$ lower, respectively, than those of the
PLA/SA textile. SA has a microporous network structure $[47,48]$. SA was embedded in PLA or MPLA when the composite material was formed. This prevented heat transfer from the outside environment or retained most of the heat within the composite, which hindered heat transfer and diffusion. In summary, the insulating properties of MPLA/SA textile were better than those of PLA/SA textile. Incorporating SA into PLA and MPLA composites decreased both the thermal conductivity and thermal diffusivity of PLA/SA and MPLA/SA textile.

\subsection{Infrared images of PLA and its composite fibers}

A FLIR infrared camera was used to obtain infrared images of PLA, PLA/SA, and MPLA/SA fabrics. The images revealed cold/heat conduction to the ambient

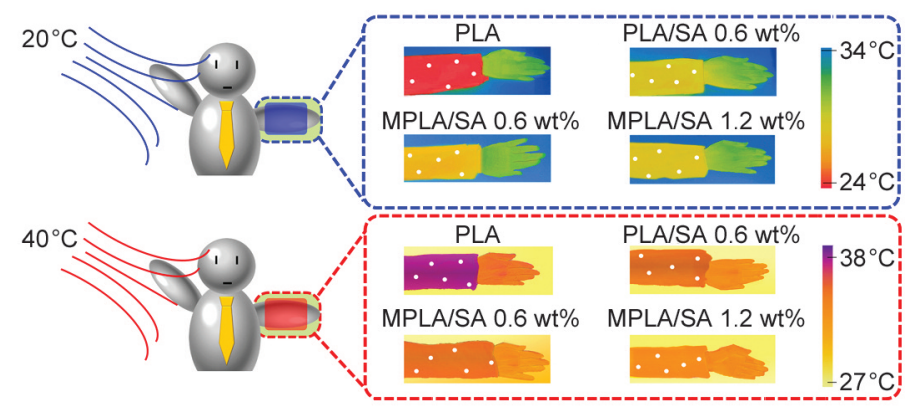

Figure 12. Infrared images of human skin covered with PLA, PLA/SA, and MPLA/SA textiles at 20 and $40^{\circ} \mathrm{C}$.

Table 5. Infrared images of PLA/SA and MPLA/SA fibers.

\begin{tabular}{|c|c|c|c|c|}
\hline \multirow{2}{*}{$\begin{array}{c}\text { SA } \\
{[\mathbf{w t} \%]}\end{array}$} & \multicolumn{2}{|c|}{$\begin{array}{c}\text { PLA/SA } \\
{\left[{ }^{\circ} \mathbf{C}\right]}\end{array}$} & $\mathbf{2 0}^{\circ} \mathbf{C}$ & $\mathbf{4 0}^{\circ} \mathbf{C}$ \\
\cline { 2 - 5 } & $\mathbf{2 0}^{\circ} \mathbf{C}$ & $37.91 \pm 0.79$ & $24.41 \pm 0.76$ & $37.84 \pm 0.80$ \\
\hline 0.0 & $24.42 \pm 0.75$ & $36.95 \pm 0.85$ & $26.06 \pm 0.84$ & $36.86 \pm 0.90$ \\
\hline 0.3 & $25.96 \pm 0.82$ & $34.86 \pm 0.87$ & $27.98 \pm 0.88$ & $34.56 \pm 0.92$ \\
\hline 0.6 & $27.66 \pm 0.86$ & $34.43 \pm 0.89$ & $28.31 \pm 0.90$ & $34.19 \pm 0.93$ \\
\hline 0.9 & $28.05 \pm 0.88$ & $34.16 \pm 0.92$ & $28.61 \pm 0.91$ & $33.85 \pm 0.93$ \\
\hline 1.2 & $28.33 \pm 0.91$ & & & \\
\hline
\end{tabular}


environment, PLA, PLA/SA, and MPLA/SA fabrics from human arms (Figure 12 and Table 5). Infrared images were obtained over $20 \mathrm{~min}$ at 20 or $40^{\circ} \mathrm{C}$. The temperature of a human arm wrapped with PLA and MPLA fabric at $20^{\circ} \mathrm{C}$ was $24.42 \pm 0.75$ and $24.41 \pm 0.76^{\circ} \mathrm{C}$, respectively. The temperature of a human arm wrapped with PLA and MPLA fabric at $40^{\circ} \mathrm{C}$ was $37.91 \pm 0.79$ and $37.84 \pm 0.80^{\circ} \mathrm{C}$, respectively. The temperatures of arms covered with PLA/ SA and MPLA/SA fabric at $20^{\circ} \mathrm{C}$ increased by about $3.2-3.6^{\circ} \mathrm{C}$ as the $\mathrm{SA}$ increased to $0.6 \mathrm{wt} \%$, and then slightly increased by about $0.6^{\circ} \mathrm{C}$ to $1.2 \mathrm{wt} \%$ (Table 5). The temperatures of arms covered with PLA/SA and MPLA/SA fabric at $40^{\circ} \mathrm{C}$ decreased by $3.0-3.3^{\circ} \mathrm{C}$ as the SA content increased to $0.6 \mathrm{wt} \%$, and then slightly decreased by about $0.7^{\circ} \mathrm{C}$ to $1.2 \mathrm{wt} \%$ (Table 5). The optimal loading of SA to minimize cold/heat conduction in PLA/SA and MPLA/SA fabric was $0.6 \mathrm{wt} \%$.

The image colors correspond to the temperature of the arm surface wrapped with PLA, PLA/SA, or MPLA/SA fabric (Figure 12). The arm wrapped with unmodified PLA fabric appeared dark red and purple at 20 and $40^{\circ} \mathrm{C}$, respectively. Arms covered with PLA/SA and MPLA/SA fabric appeared light green and brown at 20 and $40^{\circ} \mathrm{C}$, respectively. Moreover, these color changes were more obvious as the SA content increased.

The temperature of an arm covered with PLA/SA or MPLA/SA fabric tended to approach the temperature of the human body, regardless of the ambient temperature at 20 and $40^{\circ} \mathrm{C}$. The insulating properties of PLA/SA and MPLA/SA fabric were enhanced by micro-hole network formation. The micro-hole network formed by SA addition provided a long and circuitous path between the skin and the ambient environment, which resulted in decreased heat transfer $[49,50]$.

\section{Conclusions}

Unique textiles for consumer use were fabricated from environmentally friendly PLA composites. PLA, PLA/SA, and MPLA/SA fabrics were prepared, and their properties were determined. FT-IR spectra and X-ray diffractograms revealed the structures of PLA, and the PLA/SA and MPLA/SA composites. SA addition to PLA and MPLA dramatically increased the $T_{5 \%}$ of PLA/SA and MPLA/SA composites. DSC and TGA analyses also indicated improved thermal stability. The water contact angle of
PLA was significantly smaller than that of the PLA/SA and MPLA/SA composites. The SA in PLA/SA and MPLA/SA composites was the main factor that influenced the greater water resistance. Both thermal conductivity and thermal diffusivity dramatically decreased with increasing SA content for PLA/SA and MPLA/SA composites. The MPLA/SA composites had better thermal properties than the PLA/SA composites. Analysis of thermal images revealed that heat transfer in cold and hot environments was partially impeded by the SA present in the PLA/SA and MPLA/SA textiles. All of these properties provided a more comfortable temperature for human arms at 20 and $40^{\circ} \mathrm{C}$. The regulation of energy flow to the body surface from the environment through clothing is a key issue for the fabric textile industry. In that study, composite fabrics containing PLA or MPLA as a biopolymer and SA as an insulating agent were fabricated. The resulting composites displayed high tensile strength, washing durability, thermal stability, insulation, and enhanced temperature-regulating properties, and increased comfort in human arm trials. Future research will aim to design environmentally friendly thermal textiles for end-uses, such as cold-proof clothing, gloves, socks, and cushions.

\section{Acknowledgements}

The author thanks the Ministry of Science and Technology (Taipei City, Taiwan, R.O.C.) for financial support (MOST 110-2221-E-244-001-).

\section{References}

[1] Ahmed A., Hossain M. M., Adak B., Mukhopadhyay S.: Recent advances in 2D MXene integrated smart-textile interfaces for multifunctional applications. Chemistry of Materials, 32, 10296-10320 (2020).

https://doi.org/10.1021/acs.chemmater.0c03392

[2] Balasubramanian S., Kulandaisamy A. J., Babu K. J., Das A., Rayappan J. B. B.: Metal organic framework functionalized textiles as protective clothing for the detection and detoxification of chemical warfare agents https:A review. Industrial and Engineering Chemistry Research, 60, 4218-4239 (2021).

https://doi.org/10.1021/acs.iecr.0c06096

[3] Faruk M. O., Ahmed A., Jalil M. A., Islam M. T., Shamim A. M., Adak B., Hossain M. M., Mukhopadhyay S.: Functional textiles and composite based wearable thermal devices for Joule heating: Progress and perspectives. Applied Materials Today, 23, 101025 (2021). https://doi.org/10.1016/j.apmt.2021.101025 
[4] Huang Y-P., Chen T-K., Tang J-W., Yeh C., Tien C-H.: Effect of PET melt spinning on $\mathrm{TiO}_{2}$ nanoparticle aggregation and friction behavior of fiber surface. Industrial and Engineering Chemistry Research, 46, 55485554 (2007).

https://doi.org/10.1021/ie070248y

[5] Eskandarian L., Lam E., Rupnow C., Meghrazi M. A., Naguib H. E.: Robust and multifunctional conductive yarns for biomedical textile computing. ACS Applied Electronic Materials, 2, 1554-1566 (2020). https://doi.org/10.1021/acsaelm.0c00171

[6] Yan X., Cayla A., Devaux E., Otazaghine B., Salaün F.: Polypropylene/poly(vinyl alcohol) blends compatibilized with kaolinite Janus hybrid particles and their transformation into fibers. Industrial and Engineering Chemistry Research, 58, 10931-10940 (2019).

https://doi.org/10.1021/acs.iecr.9b01990

[7] Wanassi B., Azzouz B., Hassen M. B.: Value-added waste cotton yarn: Optimization of recycling process and spinning of reclaimed fibers. Industrial Crops and Products, 87, 27-32 (2016).

https://doi.org/10.1016/j.indcrop.2016.04.020

[8] Sanchis-Sebastiá M., Ruuth E., Stigsson L., Galbe M., Wallberg O.: Novel sustainable alternatives for the fashion industry: A method of chemically recycling waste textiles via acid hydrolysis. Waste Management, 121, 248-254 (2021) https://doi.org/10.1016/j.wasman.2020.12.024

[9] Pivsa-Art S., Kord-Sa-Ard J., Sijong W., Pivsa-Art W., Ohara H., Yamane H.: Biodegradation in landfilled of biodegradable micro-braided yarn. Energy Procedia, 89, 282-290 (2016). https://doi.org/10.1016/j.egypro.2016.05.036

[10] Baig G. A., Carr C. M.: Surface and structural damage to PLA fibers during textile pretreatments. Fibres and Textiles in Eastern Europe, 24, 52-58 (2015). https://doi.org/10.5604/12303666.1191427

[11] Hussain T., Tausif M., Ashraf M.: A review of progress in the dyeing of eco-friendly aliphatic polyester-based polylactic acid fabrics. Journal of Cleaner Production, 108, 476-483 (2015). https://doi.org/10.1016/j.jclepro.2015.05.126

[12] Goutianos S., van der Schueren L., Beauson J.: Failure mechanisms in unidirectional self-reinforced biobased composites based on high stiffness PLA fibres. Composites Part A: Applied Science and Manufacturing, 117, 169-179 (2019). https://doi.org/10.1016/j.compositesa.2018.11.018

[13] Maqsood M., Seide G.: Development of biobased socks from sustainable polymer and statistical modeling of their thermo-physiological properties. Journal of Cleaner Production, 197, 170-177 (2018).

https://doi.org/10.1016/j.jclepro.2018.06.191
[14] Murariu M., Doumbia A., Bonnaud L., Dechief A-L., Paint Y., Ferreira M., Campagne C., Devaux E., Dubois P.: High-performance polylactide/ $\mathrm{ZnO}$ nanocomposites designed for films and fibers with special end-use properties. Biomacromolecules, 12, 1762-1771 (2011). https://doi.org/10.1021/bm2001445

[15] Ma M., Zhou W.: Improving the hydrolysis resistance of poly(lactic acid) fiber by hydrophobic finishing. Industrial and Engineering Chemistry Research, 54, 2599-2605 (2015).

https://doi.org/10.1021/ie504814x

[16] Feng X., Pan Z., Di S., Chen Z., Chen M.: Wearable performances of lightweight PHA/PLA fiber and spun silk blended fabrics. Journal of Textile Engineering and Fashion Technology, 1, 62-66 (2017).

https://doi.org/10.15406/jteft.2017.01.00012

[17] Baghaei B., Skrifvars M.: Characterisation of polylactic acid biocomposites made from prepregs composed of woven polylactic acid/hemp-lyocell hybrid yarn fabrics. Composites Part A: Applied Science and Manufacturing, 81, 139-144 (2016).

https://doi.org/10.1016/j.compositesa.2015.10.042

[18] Randall J. P., Meador M. A. B., Jana S. C.: Tailoring mechanical properties of aerogels for aerospace applications. ACS Applied Materials and Interfaces, 3, 613626 (2011).

https://doi.org/10.1021/am200007n

[19] Ciriminna R., Fidalgo A., Pandarus V., Béland F., Ilharco L. M., Pagliaro M.: The sol-gel route to advanced silica-based materials and recent applications. Chemical Reviews, 113, 6592-6620 (2013).

https://doi.org/10.1021/cr300399c

[20] Asim N., Badiei M., Alghoul M. A., Mohammad M., Fudholi A., Akhtaruzzaman M., Amin N., Sopian K.: Biomass and industrial wastes as resource materials for aerogel preparation: Opportunities, challenges, and research directions. Industrial and Engineering Chemistry Research, 58, 17621-17645 (2019).

https://doi.org/10.1021/acs.iecr.9b02661

[21] Lin J., Li G., Liu W., Qiu R., Wei H., Zong K., Cai X.: A review of recent progress on the silica aerogel monoliths: Synthesis, reinforcement, and applications. Journal of Materials Science, 56, 10812-10833 (2021). https://doi.org/10.1007/s10853-021-05997-w

[22] Islam S. R., Yu W., Naveed T.: Influence of silica aerogels on fabric structural feature for thermal isolation properties of weft-knitted spacer fabrics. Journal of Engineered Fibers and Fabrics, 14, 1-11 (2019). https://doi.org/10.1177/1558925019866446

[23] Kiekens P., van der Burght E., Kny E., Uyar T., Milašius R.: Functional textiles - From research and development to innovations and industrial uptake. Autex Research Journal, 14, 219-225 (2014). https://doi.org/10.2478/aut-2014-0031 
[24] Farooq A. S., Zhang P.: Fundamentals, materials and strategies for personal thermal management by nextgeneration textiles. Composites Part A: Applied Science and Manufacturing, 142, 106249/ (2021).

https://doi.org/10.1016/j.compositesa.2020.106249

[25] Cai L., Peng Y., Xu J., Zhou C., Zhou C., Wu P., Lin D., Fan S., Cui Y.: Temperature regulation in colored infrared-transparent polyethylene textiles. Joule, 3, 14781486 (2019). https://doi.org/10.1016/j.joule.2019.03.015

[26] Xu C., Zhao J., Chao Z., Wang J., Wang W., Zhang X., Li Q.: Developing thermal regulating and electromagnetic shielding textiles using ultra-thin carbon nanotube films. Composites Communications, 21, 100409 (2020). https://doi.org/10.1016/j.coco.2020.100409

[27] Lan X., Wang Y., Peng J., Si Y., Ren J., Ding B., Li B.: Designing heat transfer pathways for advanced thermoregulatory textiles. Materials Today Physics, 17, 100342 (2021).

https://doi.org/10.1016/j.mtphys.2021.100342

[28] Peng Y., Cui Y.: Advanced textiles for personal thermal management and energy. Joule, 4, 724-742 (2020). https://doi.org/10.1016/j.joule.2020.02.011

[29] Wu D-Y., Wang S-S., Wu C-S.: Antibacterial properties and cytocompatibility of biobased nanofibers of fish scale gelatine, modified polylactide, and freshwater clam shell. International Journal of Biological Macromolecules, 165, 1219-1228 (2020).

https://doi.org/10.1016/j.ijbiomac.2020.10.002

[30] Wu C-S., Wu D-Y., Wang S-S.: Antibacterial properties of biobased polyester composites achieved through modification with a thermally treated waste scallop shell. ACS Applied Bio Materials, 2, 2262-2270 (2019). https://doi.org/10.1021/acsabm.9b00205

[31] Wu C-S., Wang S. S., Wu D-Y.: Textile fabrics containing recycled poly(ethylene terephthalate), oyster shells, and silica aerogels with superior heat insulation, water resistance, and antibacterial properties. ACS Applied Polymer Materials, 3, 3175-3184 (2021).

https://doi.org/10.1021/acsapm.1c00365

[32] Wu C-S., Wu D-Y., Wang S-S.: Biodegradable composite nanofiber containing fish-scale extracts. ACS Applied Bio Materials, 4, 462-469 (2021). https://doi.org/10.1021/acsabm.0c00955

[33] Wu C-S., Tsou C-H.: Fabrication, characterization, and application of biocomposites from poly(lactic acid) with renewable rice husk as reinforcement. Journal of Polymer Research, 26, 44 (2019).

https://doi.org/10.1007/s10965-019-1710-z

[34] Liu P., Gao H., Chen X., Chen D., Lv J., Han M., Cheng P., Wang G.: In situ one-step construction of monolithic silica aerogel-based composite phase change materials for thermal protection. Composites Part B: Engineering, 195, 108072 (2020).

https://doi.org/10.1016/j.compositesb.2020.108072
[35] Wu C-S.: Characterization, functionality and application of siliceous sponge spicules additive-based manufacturing biopolymer composites. Additive Manufacturing, 22, 13-20 (2018).

https://doi.org/10.1016/j.addma.2018.04.034

[36] Wu C-S., Wu D-Y., Wang S-S.: Preparation, characterization, and performance of bio based polyester composites derived from renewable distillers grains and shellfish. Journal of Polymer Research, 28, 114/1114/13 (2021).

https://doi.org/10.1007/s10965-021-02471-8

[37] Zhao C., Li Y., Ye W., Shen X., Yuan X., Ma C., Cao Y.: Performance regulation of silica aerogel powder synthesized by a two-step sol-gel process with a fast ambient pressure drying route. Journal of Non-Crystalline Solids, 567, 120923 (2021).

https://doi.org/10.1016/j.jnoncrysol.2021.120923

[38] Wu C-S.: Renewable resource-based green composites of surface-treated spent coffee grounds and polylactide: Characterisation and biodegradability. Polymer Degradation and Stability, 121, 51-59 (2015).

https://doi.org/10.1016/j.polymdegradstab.2015.08.011

[39] Wang Q., Yu H., Zhang Z., Zhao Y., Wang H.: One-pot synthesis of polymer-reinforced silica aerogels from high internal phase emulsion templates. Journal of Colloid and Interface Science, 573, 62-70 (2020).

https://doi.org/10.1016/j.jcis.2020.03.118

[40] Bozoglu D., Deligoz H., Ulutas K., Yakut S., Deger D.: Structural and dielectrical characterization of low-k polyurethane composite films with silica aerogel. Journal of Physics and Chemistry of Solids, 130, 46-47 (2019). https://doi.org/10.1016/j.jpcs.2019.02.013

[41] Mallakpour S., Naghdi M.: Polymer/SiO ${ }_{2}$ nanocomposites: Production and applications. Progress in Materials Science, 97, 409-447 (2018).

https://doi.org/10.1016/j.pmatsci.2018.04.002

[42] Yang K., Venkataraman M., Karpiskova J., Suzuki Y., Ullah S., Kim I-S., Militky J., Wang Y., Yang T., Wiener J., Zhu G., Yao J.: Structural analysis of embedding polyethylene glycol in silica aerogel. Microporous and Mesoporous Materials, 310, 110636 (2021).

https://doi.org/10.1016/j.micromeso.2020.110636

[43] Wang W., Du L., Xie Y., Zhang F., Li P., Xie F., Wan X., Pei Q., Leng J., Wang N.: Bioinspired four-dimensional polymeric aerogel with programmable temporal-spatial multiscale structure and functionality. Composites Science and Technology, 206, 108677 (2021).

https://doi.org/10.1016/j.compscitech.2021.108677

[44] Follmann H. D. M., Oliveira O. N. Jr., Martins A. C., Lazarin-Bidóia D., Nakamura C. V., Rubira A. F., Silva R., Asefa T.: Nanofibrous silica microparticles/polymer hybrid aerogels for sustained delivery of poorly watersoluble camptothecin. Journal of Colloid and Interface Science, 567, 92-102 (2020). https://doi.org/10.1016/j.jcis.2020.01.110 
[45] Mazrouei-Sebdani Z., Begum H., Schoenwald S., Horoshenkov K. V., Malfait W. J.: A review on silica aerogel-based materials for acoustic applications. Journal of Non-Crystalline Solids, 562, 120770 (2021). https://doi.org/10.1016/j.jnoncrysol.2021.120770

[46] Kaya G. G., Deveci H.: Synergistic effects of silica aerogels/xerogels on properties of polymer composites: A review. Journal of Industrial and Engineering Chemistry, 89, 13-27 (2020). https://doi.org/10.1016/j.jiec.2020.05.019

[47] Cai H., Jiang Y., Feng J., Zhang S., Peng F., Xiao Y., Li L., Feng J.: Preparation of silica aerogels with high temperature resistance and low thermal conductivity by monodispersed silica sol. Materials and Design, 191, 108640 (2020).

https://doi.org/10.1016/j.matdes.2020.108640
[48] Zhang Y., Xiang L., Shen Q., Li X., Wu T., Zhang J., Nie C.: Rapid synthesis of dual-mesoporous silica aerogel with excellent adsorption capacity and ultra-low thermal conductivity. Journal of Non-Crystalline Solids, 555, 120547 (2021).

https://doi.org/10.1016/j.jnoncrysol.2020.120547

[49] Lamy-Mendes A., Pontinha A. D. R., Alves P., Santos P., Durães L.: Progress in silica aerogel-containing materials for buildings' thermal insulation. Construction and Building Materials, 286, 122815 (2021).

https://doi.org/10.1016/j.conbuildmat.2021.122815

[50] Mishra R., Behera B. K., Muller M., Petru M.: Finite element modeling based thermodynamic simulation of aerogel embedded nonwoven thermal insulation material. International Journal of Thermal Sciences, 164, 106898 (2021).

https://doi.org/10.1016/j.ijthermalsci.2021.106898 